\title{
Mental health and the civil conflicts in Sudan
}

\author{
Abdelazim Ali, ${ }^{1}$ Mahmoud Saeed ${ }^{2}$ and Saoud Sultan ${ }^{3}$
}

${ }^{1}$ Cwm Taf Health Board, UK

\section{${ }^{2}$ Consultant Psychiatrist,}

Birmingham and Solihull Mental

Health NHS Foundation Trust

UK, email Mahmoud.Saeed@

bsmhft.nhs.uk

${ }^{3}$ Consultant Psychiatrist and

College Tutor, North East London NHS Foundation Trust, UK
Sudan has endured the longest civil war in the history of Africa. The conflict between the northern (mainly Arab) and southern (mainly sub-Saharan African) populations started in 1983, and in its first phase continued for 22 years. The combination of civil war and famine has taken the lives of nearly 2 million people and displaced an estimated 4 million people from their villages and homes. This paper presents some data on the prevalence of mental disorder and the mental health service response to the situation.

Since July 2011, Sudan has been divided into two states, Sudan and South Sudan, following a peace agreement signed in 2005. However, since this separation, conflict has begun between the two countries for control of the town of Abyei, which sits within a disputed region, rich with oil, on the border between the two. A conflict had already started in the region of Darfur, lying in the far west of northern Sudan, in 2003, and has continued to this date. According to the United Nations (2007), over 2.5 million civilians have been displaced from Darfur and the death toll is variously estimated to lie between 200000 and 400000 , including many women and children. Not only that, but other parts of Sudan have also been affected by the long and exhausting civil conflicts, with shortages of water and food, and ultimately widespread famine. Thousands of people have become refugees. The extended civil conflict and war have undoubtedly had a negative impact on the country's economy and consequently on the health services, including mental health services.

\section{Prevalence of mental disorder}

Studies have shown that the incidence rates of certain psychiatric conditions, notably depression and post-traumatic stress disorder (PTSD), substantially increased as a consequence of the civil conflicts in Sudan. For example, Roberts et al (2009) carried out a cross-sectional survey of a random sample of the general population in Juba city, the capital of South Sudan, with a sample of 1242 adults. Levels of exposure to traumatic events and the prevalence of PTSD were measured using the Harvard Trauma Questionnaire and the presence of depressive illness was measured using the Hopkins Symptom Checklist. Over a third (36.2\%) of respondents met the criteria for PTSD and more than half (58.7\%) the criteria for depression.

A study of the impact of trauma on the NgokDinka, the native people of South Sudan living in the town of Abyei, was conducted by Kush Inc. (Campbell, 2012). This survey reported that within the population displaced by the conflict, $38 \%$ overall, and $51 \%$ of women, met criteria for PTSD. We do not have any statistics about the prevalence of PTSD or of depression in the general population of Sudan before the conflict, but in the UK, by way of comparison, the lifetime prevalence of PTSD is just $1-9 \%$, and that of depression $5.8 \%$.

All people displaced as a consequence of conflict are affected by mental health problems to some degree, but women and children are more seriously affected. Kim et al (2007) carried out a study in January 2005 among six camps for displaced persons in Nyala District, Darfur. They used systematic random sampling to select 1253 women and asked them about their mental health and general health status as well as their opinions on women's rights. The investigators found that the prevalence of major depression was $31 \%$. Women expressed concerns about their limited rights arising out of the constraints of marriage, lack of freedom of movement and limited access to healthcare. The study also found that $98 \%$ of women meeting criteria for depressive illness felt that counselling provided by international agencies would be the most helpful form of treatment. These findings confirm that the prevalence of mental illnesses such as depression increases as the result of civil conflict. They also stress the importance of counselling as a potentially useful treatment option.

\section{Services}

The mental health services in Sudan, before and during these conflicts, were lacking human and other resources to handle the high demand, and to date that position remains unchanged. Mental health services are not a priority for government, and their availability varies considerably from one region to another. In the capital Khartoum, in the east of Sudan, the situation is better than in other regions, because there are established psychiatric hospitals and mental health professionals in the capital.

In a report by the Sudanese Psychiatrists Association (2006), the following problems were highlighted: 
- The prevalence, incidence, pattern and trends of mental illnesses are not adequately known due to limited sources of information.

- Mental health services coverage is low. Outside of Khartoum State, the service is limited to nine urban areas and services are almost absent at provincial and district levels; there is no coordination across centres.

- Mental illness still carries a social stigma and help-seeking tends to happen only at late stages of illness.

- Patients with psychiatric disorders consult spiritual healers first. Psychotropic drugs are not available at an affordable price. Children with psychiatric disorders are often taken to see paediatricians and general practitioners.

- Long-standing conflicts and political instability causing large-scale population displacement have resulted in an increase in immediate and future health hazards, particularly in populations who are living in temporary settlements.

- Some 150-200 qualified Sudanese psychiatrists have moved abroad, and this brain drain is a persistent and continuing problem.

\section{What is needed now}

In order to ensure there is sufficient and effective provision of mental health services to the population affected by the civil conflicts in all parts of Sudan, community surveys should be carried out, to determine the prevalence of different mental disorders and specific service needs. A holistic approach needs to be adopted to ensure delivery of efficient care packages to all affected individuals. Such care packages should take into consideration the basic needs of individuals, such as suitable accommodation, clean water, electricity and good ventilation. The physical health needs of the population must also be addressed adequately in order to improve their mental health. Other needs, such as education, finance and a sense of security must be met to ensure a good response to any psychological help that can be offered. One suggestion has been to introduce mobile community mental health units to refugees in camps, to assess and address any mental health needs. Mental health professionals - psychiatrists, psychologists, social workers and nurses - should be present in each unit, with all the necessary resources to provide a community-based service. A local in-patient unit should be available for patients who need to be hospitalised.

Although various international organisations have been working hard to provide services for displaced persons and refugee populations in Sudan, there is still a significant gap between the services provided and actual demand. The situation is likely to deteriorate further following the outbreak of civil war in South Kordufan (in Sudan but close to the border with South Sudan) and the Upper Blue Nile regions (in South Sudan) in addition to the ongoing conflict in Darfur.

\section{References}

Campbell, J. (2012) KUSH investigation: psychological capacity of the Ngok Dinka. Frontiers of Peace website, http://www. frontiersofpeace.com/?p=1612 (accessed June 2013).

Kim, G., Rabih, T. \& Lawry, L. (2007) Basic health, women's health, and mental health among internally displaced persons in Nyala Province, South Darfur, Sudan. American Journal of Public Health, 97, 353-361.

Roberts, B., Damundu E. Y., Lomoro, O., et al (2009) Post-conflict mental health needs: a cross-sectional survey of trauma, depression and associated factors in Juba, Southern Sudan. BMC Psychiatry, $9,7$.

Sudanese Psychiatrists Association (2006) Sudan Mental Health Draft National Policy. Available at http://www.sudanesepsychiatrists. org.uk/pdf/sudan_mh.pdf) (accessed June 2013).

United Nations (2007) The United Nations and Darfur: fact sheet. Available at http://www.unis.unvienna.org/pdf/UN-Darfur_fact_ sheet.pdf (accessed June 2013)

See also

Sudanese Psychiatrists Association website http://www. sudanesepsychiatrists.org.uk/main (accessed June 2013).
MENTAL HEALTHLAW PROFILES

\title{
Mental health law profiles
}

\author{
George Ikkos
}

Consultant Psychiatrist in Liaison Psychiatry, Royal National Orthopaedic Hospital, London, UK, email ikkos@doctors.org.uk
Empires come and go. Both Hungary and Serbia were part of the Austro-Hungarian and Communist empires. Although these empires have gone, on the evidence of the reviews published in this issue, their legacy, in terms of culture, law and institutions, remains. The authors highlight that, on the negative side, this legacy includes stigma and the neglect of people with mental illness, although these are hardly exclusive to these countries.

Effective protection in law, including guaranteed access to mental health services, is an essential component of ensuring parity between physical and mental illness. The contributions to this issue on mental health law profiles differ in focus, with Kurimay and Vizi focusing on such provision in law as exists at present and advocating change for the future, while Lecic Tosevski et al demonstrate the complexities of attempting to change the law, something that must always happen in political contexts and with political processes. In this context, the 'Enhancing social cohesion through strengthening community care' project as part of the Stability Pact for South Eastern Europe appears noteworthy. 